\title{
A Rare Finding: A Left Atrial Cavernous Haemangioma
}

\author{
Authors: \\ *Hannah Gower, ${ }^{1}$ Jingzhou He, ${ }^{1,2}$ Timothy Davies, ${ }^{1}$ Anish George \\ 1. Department of Cardiology, Royal Devon and Exeter NHS Foundation Trust, UK \\ 2. Diabetes and Vascular Medicine Research Centre, University of Exeter, UK \\ *Correspondence to hannahgower@nhs.net \\ Disclosure: $\quad$ The authors have declared no conflicts of interest. \\ Received: $\quad 10.01 .21$ \\ Accepted: $\quad 30.03 .21$ \\ Keywords: $\quad$ Cardiac MRI (cMRI), cavernous haemangioma, heart neoplasms. \\ Citation: $\quad$ EMJ Int Cardiol. 2021;9[1]:58-63.
}

\section{Abstract}

Background: Cardiac haemangiomas are extremely rare, benign tumours that can arise from any heart structures. Although patients may present with a range of symptoms, the majority are asymptomatic and picked up incidentally on imaging or at autopsy. Echocardiography, cardiac MRI, and coronary angiography are the main imaging modalities for diagnostic work-up. Surgical resection is the recommended treatment, with good post-operative outcomes.

Case Presentation: The authors present a case of a 69-year-old female with a subacute history of dyspnoea and weight loss. A CT scan to screen for malignancy revealed a possible filling defect within a prominent left atrial appendage. Further cardiac imaging with transoesophageal echocardiography and cardiac MRI confirmed a mass in the left atrium, which was initially thought to be an atrial myxoma. Following successful surgical resection, histology demonstrated characteristic features of a benign cavernous haemangioma.

Conclusion: The authors present a rare finding of a cardiac cavernous haemangioma. Although cardiac haemangiomas are more often found on the right side of the heart, this case demonstrates a left atrial appendage haemangioma, which is very unusual. The importance of multimodality imaging is also demonstrated. Definitive treatment is surgery, with follow-up often involving surveillance transthoracic echocardiography to ensure no recurrence.

\section{BACKGROUND}

While cardiac tumours have been documented since the 1500s, first featuring in Italian anatomist and surgeon Colombo's 'De re anatomica' ('On Things Anatomical')', not until 1952 that Banhson and Newman performed the first successful open surgical excision of a primary cardiac tumour, followed by Crafoord et al. in 1954 using a cardiopulmonary bypass. 3,4

The incidence of primary cardiac tumours discovered at autopsy is around $0.02 \%$, with $75 \%$ of these being histologically benign. ${ }^{5}$ Cardiac haemangiomas are extremely rare, accounting for approximately $1-2 \%$ of all primary cardiac tumours. They are benign vascular tumours that can occur in any chamber of the heart, predominantly on the right side, with only $7 \%$ of cases arising from the left atrium, which was seen in this case. ${ }^{6,7}$ They may occur in any of the three cardiac layers: the 
endocardium, myocardium, and pericardium. They are rarely found in the intra-atrial septum, intraventricular septum, or on the valves.

Cardiac haemangiomas are characterised microscopically by benign proliferative endothelial cells lining blood vessels, with increased vascularisation. ${ }^{6}$ They are classified into three subgroups, according to histological appearances: cavernous (composed of vessels with wide lumens), capillary, and arteriovenous malformations (angiodysplasias), ${ }^{8,9}$

As patients are commonly asymptomatic, cardiac haemangiomas are often discovered incidentally on imaging or revealed during autopsy. However, depending on the anatomical location of the tumour, patients can present with breathlessness, congestive heart failure, chest pain, syncope, pericardial effusion, and valve stenosis. Although benign histologically, if left untreated, cardiac haemangiomas can rupture or give rise to conductive and haemodynamic abnormalities, resulting in significant morbidity and mortality. ${ }^{10}$ Therefore, surgical resection is the treatment of choice. There are case reports of conservative management approaches without obvious major complications in adults where resection was deemed too high-risk..$^{11,12}$

\section{CASE PRESENTATION}

A 69-year-old female was referred by her general practitioner to an elderly care clinic with worsening exertional dyspnoea and fatigue for 3 months. She also reported an unexplained $3 \mathrm{~kg}$ weight loss in the same period, with no change in her lifestyle to account for this. Her exercise tolerance was unlimited on flat ground; however, she could only complete a flight of stairs at a slow pace, being limited by fatigue and breathlessness.

Her past medical history included chronic obstructive pulmonary disease, breast fibroadenoma, kidney stones, solitary lipoma removal, and a recent diagnosis of paroxysmal atrial fibrillation. She was an ex-smoker (20 pack-years) and had a family history of diabetes and stroke. Her medication history included lansoprazole, inhaled tiotropium, inhaled budesonide and formoterol fumarate, inhaled salbutamol, and flecainide. Physical examination was normal, with a blood pressure of 137/80 $\mathrm{mmHg}$ and a regular heart rate of 67 beats per minute.

\section{INVESTIGATIONS}

Baseline investigations demonstrated normal renal function, full blood count, C-reactive protein, plasma viscosity, bone profile, CA125, liver function, thyroid function, vitamin B12, and folate. Her ferritin was only mildly raised at $167 \mu \mathrm{g} / \mathrm{L}$. Chest X-ray showed emphysematous changes.

A CT scan of the chest, abdomen, and pelvis to screen for malignancy demonstrated a prominent atrial appendage, with a possible filling defect (Figure 1A). There was no evidence of lymphadenopathy. Given the recent diagnosis of atrial fibrillation, the mass was initially considered to be a thrombus. Transoesophageal echocardiography (Figure 1C) did not clearly show the left atrial appendage (LAA) as it appeared either compressed externally or largely replaced/full of a mass. The mass appeared heterogeneous and larger than her CT at $39 \times 60 \mathrm{~mm}$. There was no obvious invasion into surrounding structures and one view showed flow within. There were no other structural abnormalities.

She went on to have a cardiac MRI (cMRI; Figure 1D). This showed a mass originating from within the LAA and measuring approximately $50 \times 35 \mathrm{~mm}$, with no invasion beyond this. There was homogeneous signal on T1-weighted sequences, some heterogeneity on T2-weighted sequences, and hyperintensity on T2 short tau inversion recovery (fat saturation) sequences (Figure 2). Real-time imaging during gadolinium administration suggested some perfusion but not extremely brisk. In the early phase following gadolinium there was heterogeneity, with some uptake and other areas which appeared avascular. There was no significant compression of other cardiac or vascular structures. The mass most likely represented a LAA myxoma with possible thrombus.

Given her progressive dyspnoea and the potential risk of life-threatening complications such as embolism and arrhythmia, she was referred for surgical excision of the LAA mass. 


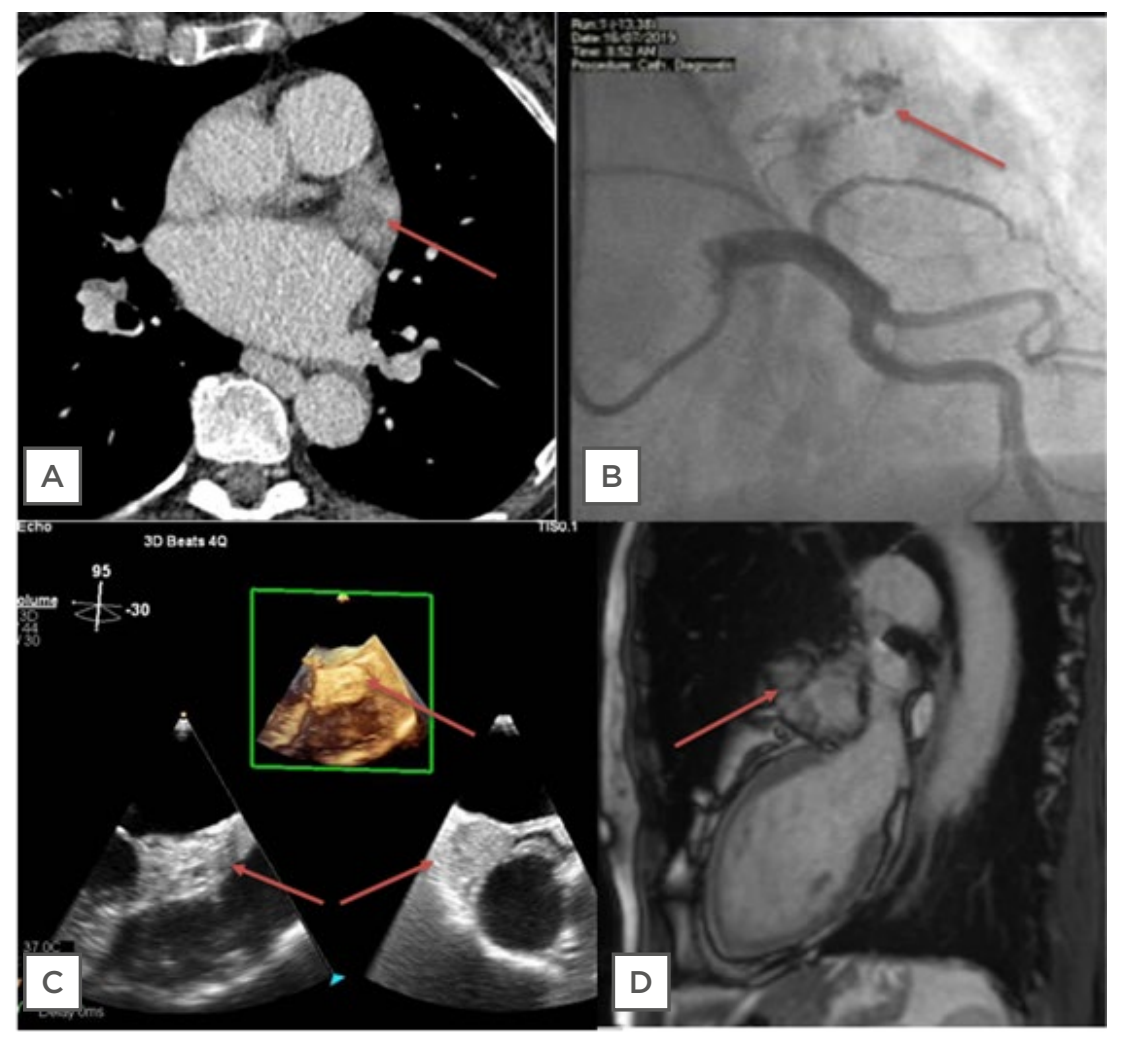

Figure 1: Imaging modalities, with cardiac mass highlighted by red arrow. A) Transverse section on CT; B) right anterior oblique cranial view on angiography showing neovascular formation supplying haemangioma; C) transoesophageal echocardiography with 3D imaging showing a left atrium mass; D) sagittal section on cardiac MRI.
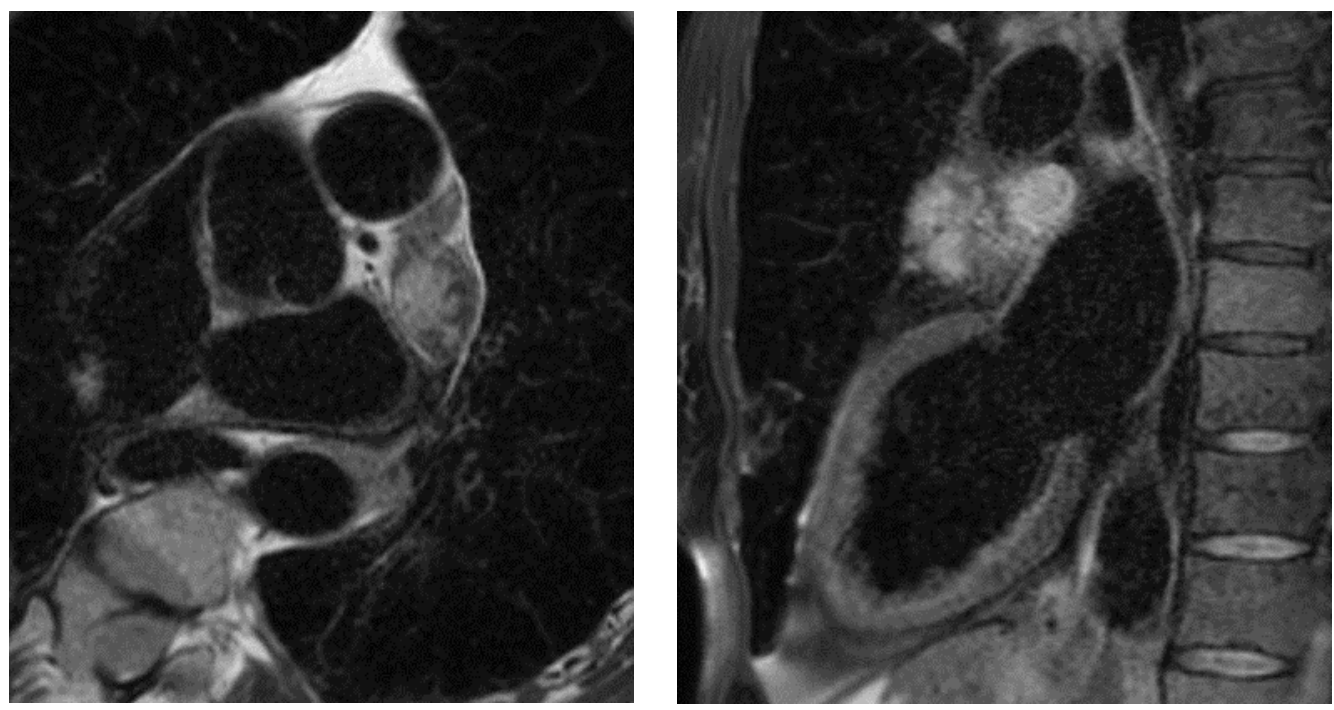

Figure 2: T2 STIR MRI images with fat suppression. A) Transverse section; B) sagittal section. STIR: short tau inversion recovery. 
She subsequently underwent coronary angiography as a work-up for surgery. This demonstrated normal coronary arteries and a vascular blush through the tumour (Figure 1B).

\section{TREATMENT}

She underwent surgical resection, and histology demonstrated sections of atrium containing a well-circumscribed lesion, comprising multiple thick- and thin-walled blood-filled vascular channels, with foci of papillary endothelial hyperplasia. There was no evidence of atypia or necrosis. The histological findings were characteristic of a benign cavernous haemangioma.

Following surgery, she was repatriated to the local district general hospital for postoperative rehabilitation, which was complicated by hospital-acquired pneumonia requiring intravenous antibiotics and pulmonary oedema requiring treatment with intravenous administration of furosemide.

In a 3-month follow-up clinic she reported a reduction in peripheral limb oedema but ongoing breathlessness and chest tightness. This was attributed to resolving pleural effusions and chronic obstructive pulmonary disease. Unfortunately, the patient developed recurrent chest infections and is under the respiratory team for further follow-up. A 1-year follow-up transthoracic echocardiogram demonstrated no recurrence of the haemangioma.

\section{DISCUSSION}

Cardiac haemangiomas are rare benign cardiac tumours that are histologically like that of their extracardiac counterparts. They develop from proliferation of endothelial cells and pericytes. As mentioned previously, they can be divided into three subgroups: cavernous, capillary, and arteriovenous malformations. The histological appearances of the capillary subgroup demonstrate a myxoid matrix with capillary-sized vessels, endothelial cells, pericytes, and fibroblasts. The cavernous pattern consists of large, dilated vascular spaces with either thick or thin walls. Lastly, the arteriovenous pattern is characterised by heterogeneous dysplastic vessel types with muscularised vessels or irregular, thickened wall diameter and, on occasion, containing fibrous and fat tissue. However, cardiac haemangiomas may be a combination of the three patterns. Immunohistochemistry can reveal expression of typical endothelial markers including CD31, CD34, and factor VIII.

Cardiac haemangiomas, including cavernous haemangiomas, are generally sporadic in nature and can be found in all areas of the heart but rarely in the epicardium or valves. ${ }^{9,13}$ The authors' case demonstrated a cardiac haemangioma in the LAA, which is very rare. Han $Y$ et al. ${ }^{14}$ reviewed 56 cases and found that most cardiac haemangiomas were found on the right side of the heart, with $7 \%$ seen in the left atrium. Cardiac cavernous haemangiomas are slightly more commonly seen in females and can occur at any age. ${ }^{10}$

There are several cardiac imaging modalities available for the work-up of a suspected cardiac tumour, each with varying benefits and limitations (Table 1). Transthoracic echocardiography is an effective, non-invasive investigation with a sensitivity of $93 \%$ and is particularly useful in diagnosing tumours within the ventricles. Transoesophageal echocardiography provides a slightly more effective diagnostic modality, particularly for tumours within the atria ( $97 \%$ sensitivity). ${ }^{13}$ Echocardiography in general can be utilised to assess size, morphology, attachments to adjacent structures, extension, and haemodynamic effects and can improve intracavity definition, assess vascularity, and exclude thrombus. CT is established in its use to assess chest and lung tissue and corresponding vascular structures, assess masses involving the coronaries, and exclude coronary artery disease and calcified masses. PET can be useful for differentiating between benign and malignant lesions, staging malignancies, optimising biopsy location, and planning radiotherapy in certain circumstances. CMRI is considered the gold standard imaging modality for assessing possible cardiac tumours. It is non-invasive and produces high-resolution images without using ionising radiation. ${ }^{15}$ 
Table 1: Advantages and disadvantages of different imaging modalities for assessment of a suspected cardiac tumour.

\begin{tabular}{|c|c|c|}
\hline Imaging Modality & Advantages & Disadvantages \\
\hline TTE & $\begin{array}{l}\text { Non-invasive } \\
93 \% \text { sensitivity } \\
\text { More effective for the evaluation of } \\
\text { ventricle-based tumours } \\
\text { Real-time observation } \\
\text { Does not require contrast material or } \\
\text { radiation exposure } \\
\text { Low cost and portable }\end{array}$ & $\begin{array}{l}\text { Less specific than MRI in soft } \\
\text { tissue characterisation, including } \\
\text { differentiation between tumour and } \\
\text { thrombus } \\
\text { Image quality affected by body } \\
\text { habitus and lung pathology (e.g., } \\
\text { emphysema) } \\
\text { Tumour size may be difficult to } \\
\text { quantify } \\
\text { Tumour origin, such as from the } \\
\text { superior vena cava or branch } \\
\text { pulmonary vessels, may not be } \\
\text { identifiable } \\
\text { Limited assessment of extracardiac } \\
\text { structures }\end{array}$ \\
\hline TOE & $\begin{array}{l}97 \% \text { sensitivity } \\
\text { Good views of the atria and LAA } \\
\text { Real-time observation } \\
\text { Does not require contrast material or } \\
\text { radiation exposure } \\
\text { Effective in differentiating structural } \\
\text { features, such as site of attachment }\end{array}$ & $\begin{array}{l}\text { Invasive procedure } \\
\text { Less specific than MRI in soft tissue } \\
\text { characterisation } \\
\text { May require sedation or general } \\
\text { anaesthetic } \\
\text { Limited assessment of extracardiac } \\
\text { structures }\end{array}$ \\
\hline CT & $\begin{array}{l}\text { Non-invasive } \\
\text { Allows assessment of nearby } \\
\text { structures } \\
\text { Exclusion of coronary artery disease } \\
\text { and calcified masses } \\
\text { Fast acquisition times } \\
\text { Cancer staging }\end{array}$ & $\begin{array}{l}\text { Radiation exposure } \\
\text { Risk of contrast-induced nephropathy } \\
\text { Less effective than MRI at evaluating } \\
\text { soft tissue structures }\end{array}$ \\
\hline PET & $\begin{array}{l}\text { Non-invasive } \\
\text { Differentiating benign and malignant } \\
\text { lesions, especially when combined } \\
\text { with MRI } \\
\text { Biopsy location and radiotherapy } \\
\text { planning }\end{array}$ & $\begin{array}{l}\text { Can lack anatomical information } \\
\text { Small tumours may not be detectable } \\
\text { Involves a radioactive element } \\
\text { Limited availability in some centres } \\
\text { Affected by blood sugar levels and } \\
\text { oral intake timings }\end{array}$ \\
\hline CMRI & $\begin{array}{l}\text { Non-invasive } \\
\text { High-resolution images } \\
\text { Does not use ionising radiation } \\
\text { Gold standard for evaluation for } \\
\text { possible cardiac tumours } \\
\text { Evaluating tumour vascularity }\end{array}$ & $\begin{array}{l}\text { Requires contrast material } \\
\text { Long acquisition times } \\
\text { Limited availability } \\
\text { Contraindications include } \\
\text { claustrophobia and older generation } \\
\text { cardiac devices }\end{array}$ \\
\hline Coronary angiography & $\begin{array}{l}\text { Assessment of coronary artery disease } \\
\text { prior to surgical intervention } \\
\text { Can demonstrate tumour blood flow }\end{array}$ & $\begin{array}{l}\text { Invasive with risk of complications } \\
\text { Limited assessment of tumour size, } \\
\text { structure, and extension }\end{array}$ \\
\hline
\end{tabular}

CMRI: cardiac MRI; LAA: left atrial appendage; PET: positron emission tomography; TOE: transoesophageal echocardiography; TTE: transthoracic echocardiography. 
cMRI can effectively assess morphology, dimensions, location, extension, and infiltration into adjacent tissue, and characterise histopathology. ${ }^{16}$ Coronary angiography is useful pre-operatively to assess for coronary artery disease as coronary artery bypass grafting can be undertaken at the same time as resecting the tumour. It can also demonstrate the blood supply to the tumour and reveal the characteristic vascular blush, which is associated with many cardiac tumours. Interestingly, the vascular blush seen with most cardiac tumours, including haemangiomas, is not typically associated with the cavernous subtype because of the large vascular spaces that promote very slow flow. ${ }^{11}$ However, coronary angiography did reveal this finding in the authors' case.

Tumour resection can occur under extracorporeal membrane oxygenation installed using aortic and bicaval venous cannulation, with concomitant valve surgery if required. Post-operative complications may include arrhythmia, major bleeding into the chest, renal dysfunction, and wound infection. As a consequence of the low incidence of haemangiomas, large cohort published studies are rare in regard to postoperative survival; however, one article reported survival following resection similar to a standard population but recommended close follow-up with annual echocardiography for the first 4 years minimally. ${ }^{17}$

\section{LEARNING POINTS}

Cardiac cavernous haemangiomas are rare benign tumours more commonly seen in the right heart; this case demonstrated a LAA cavernous haemangioma, which was unusual. Surgical resection is the recommended approach to management to relieve symptoms and reduce the risk of life-threatening complications, including tumour rupture, embolism, arrhythmia, and haemodynamic compromise. There are a number of imaging modalities to assess cardiac tumours. CMRI remains the gold standard for assessment because of its non-invasive nature and production of high-resolution images.

\section{References}

1. Encyclopedia Britannica. Matteo Realdo Colombo. Encyclopedia. 2020. Available at: https://www. britannica.com/biography/MatteoRealdo-Colombo. Last accessed: 18 September 2020.

2. Colombo R. Realdi Colvmbi Cremonensis De re anatomica libri $X V(1559)$ 1st edition, Venice: Nicolo Bevilacqua.

3. Bahnson $\mathrm{H}$ et al. Diagnosis and treatment of intracapvitary myxomas of the heart. Ann Surg. 1957;145(6):915-26.

4. Chitwood W. Clarence Crafoord and the first successful resection of a cardiac myxoma. Ann Thorac Surg. 1992;54(5):997-8.

5. European Society of Cardiology (ESC). Cardiac tumors. 2020. Available at: https://www.escardio. org/Education/Practice-Tools/EACVItoolboxes/3D-Echo/cardiac-tumors. Last accessed: 18 September 2020.
6. Li W et al. Cardiac hemangioma: a comprehensive analysis of 200 cases. Ann Thorac Surg. 2021;99(6):P224652.

7. Abuharb M et al. Epicardial cardiac cavernous haemangioma-a case report. BMC Cardiovasc Disord. 2019;19(1):179.

8. Lucena $\mathrm{J}$ et al (eds.), ClinicoPathological Atlas of Cardiovascular Diseases (2015), Cham: Springer International Publishing.

9. Hong $\mathrm{S}$ et al. Cardiac hemangioma: a case report. Korean J Thorac Cardiovasc Surg. 2014;47(2):149-51.

10. Thomas JE et al. Asymptomatic right atrial cavernous hemangioma: a case report and review of the literature. Cardiovasc Pathol. 2004;13(6):341-4.

11. Gribaa R et al. Conservative management of cardiac hemangioma for 11 years. Tex Heart Inst J. 2015;42(5):450-3.
12. Tomizawa $Y$ et al. Reconstruction of the left ventricle in a patient with cardiac hemangioma at the apex. Ann Thorac Surg. 2001;71(6):2032-4.

13. Arakelyanz AA et al. Cardiac tumours - a brief review. Br J Cardiol. 2020;27:24-5.

14. Han $Y$ et al. Cardiac capillary hemangioma: a case report and brief review of the literature. J Clin Ultrasound. 2014;42(1):53-6.

15. Bluemke $D$ et al. Noninvasive coronary artery imaging. Circulation. 2008;118(5):586-606.

16. Tyebally $\mathrm{S}$ et al. Cardiac tumors: JACC cardio oncology state-ofthe-art review. JACC CardioOncol. 2020;2(2):293-311.

17. Yin $L$ et al. Surgical treatment of cardiac tumors: a 5-year experience from a single cardiac center. J Thorac Dis. 2016;8(5):911-9. 